\title{
Monte Carlo simulation of signals in digital diaphanoscopy of the maxillary sinuses
}

Bryanskaya, E., Gneushev, R. Yu., Makovik, I., Dremin, V., Bukin, A., et al.

E. O. Bryanskaya, R. Yu. Gneushev, I. N. Makovik, V. V. Dremin, A. G. Bukin, O. A. Bibikova, B. M. Shuraev, O. Minet, U. Zabarylo, A. V. Dunaev, V. G. Artyushenko, "Monte Carlo simulation of signals in digital diaphanoscopy of the maxillary sinuses," Proc. SPIE 11457, Saratov Fall Meeting 2019: Optical and Nano-Technologies for Biology and Medicine, 114571K (9 April 2020); doi: $10.1117 / 12.2564314$

EDent: Saratov Fall Meeting 2019: VII International Symposium on Optics and Biophotonics, 2019, Saratov, Russian Federation 


\title{
Monte Carlo simulation of signals in digital diaphanoscopy of the maxillary sinuses
}

\author{
E.O. Bryanskayaa , R.Yu. Gneusheva, I.N. Makovik ${ }^{\mathrm{a}, \mathrm{b}}$, V.V. Dremin ${ }^{\mathrm{a}, \mathrm{c}}$, A.G. Bukin ${ }^{\mathrm{d}}$, O.A. Bibikova ${ }^{\mathrm{b}}$, \\ B.M. Shuraev ${ }^{\mathrm{e}}$, O. Minet ${ }^{\mathrm{f}}$, U. Zabarylo ${ }^{\mathrm{g}}$, A.V. Dunaev ${ }^{\mathrm{a}}$, V.G. Artyushenko ${ }^{\mathrm{b}}$ \\ ${ }^{a}$ Research and Development Center of Biomedical Photonics, Orel State University named after I.S. \\ Turgenev, Orel, 302026, Russia \\ ${ }^{b}$ art photonics $\mathrm{GmbH}$, Berlin, 12489, Germany \\ 'Opto-Electronics and Measurement Techniques Unit, Faculty of Information Technology and \\ Electrical Engineering, University of Oulu, Oulu, 90570, Finland \\ ${ }^{\mathrm{d} I n s t i t u t e}$ of Engineering Physics, Serpukhov, 142210, Russia \\ 'Diagnostic Medical Center "MediScan”, Orel, 302030, Russia \\ ${ }^{\mathrm{f} C}$ Charité Universitätsmedizin Berlin, Berlin, 12203, Germany \\ ${ }^{\mathrm{g}}$ Charité - Universitätsklinikum Berlin, Berlin, 13353, Germany
}

\begin{abstract}
Digital diaphanoscopy method has potential to separate normal and pathological conditions of the maxillary sinuses. The entirety of all the features of the investigated area (the presence or absence of pathology, its etiology and morphological features) affects the resulting images of the maxillary sinuses by the digital diaphanoscopy. In this work, the MonteCarlo numerical simulation method was used to determine the patterns of propagation of light radiation in biological tissue. A biologically heterogeneous environment, represented by structures of the skull and maxillary sinuses, as well as pathological changes in them was modelled in the TracePro software.
\end{abstract}

Keywords: optical diagnostics, digital diaphanoscopy, paranasal sinuses, inflammatory diseases, Monte Carlo method, biological optical properties

\section{INTRODUCTION}

Diagnosis of inflammatory diseases of the paranasal sinuses is one of the urgent problems of modern otolaryngology ${ }^{1}$. Nowadays the standard methods to identify these pathologies include radiography, computed tomography, magnetic resonance imaging, rhinoscopy and ultrasound. However, due to use of carcinogenic roentgen radiation during the study, a high level of false-negative results and painfulness of the diagnostic procedures, application of these methods is limited and often impossible in the diagnoses of pregnant women and children ${ }^{2}$.

Recently, non-invasive optical technologies have been widely used to diagnose pathological conditions in various fields of medicine. Thus, the method of digital diaphanoscopy seems promising for the separation of the normal and pathological conditions (inflammation, cystic and tumor tissues) of the maxillary sinuses. The method is based on the visualization of scattering patterns of low-intensity radiation as it passes through the maxillary sinuses.

The object of study is represented by various tissues of the skull and maxillary sinuses and has a complex organization. The optical properties of biological layers, in particular, absorption and scattering coefficients ${ }^{3,4}$, vary in depends on the anatomical and gender characteristics of patients ${ }^{5,6}$, and on the presence of pathological changes. The conducted preliminary experimental studies showed a strong influence on the diagnostic result of changes in these parameters ${ }^{7}$. Based on this, the aim of the study was to determine the patterns of change in the probe signal level for various anatomical and optical properties of the object of study. The identification of this pattern will help to modernize the instrumental implementation of a digital diaphanoscope and obtain a new diagnostic criterion for determining various pathological conditions of the maxillary sinuses.

*bryanskayae@ mail.ru; phone 74862 419837; bmecenter.ru/en 


\section{MATERIAL AND METHODS}

The construction of the 3-D model was based on the Monte Carlo methodology, which remains one of the most effective simulation tools when dealing with biological tissues. The simulation was carried out in the TracePro (Lambda Software $)^{8-10}$. Figure 1 shows a scheme of the developed model.

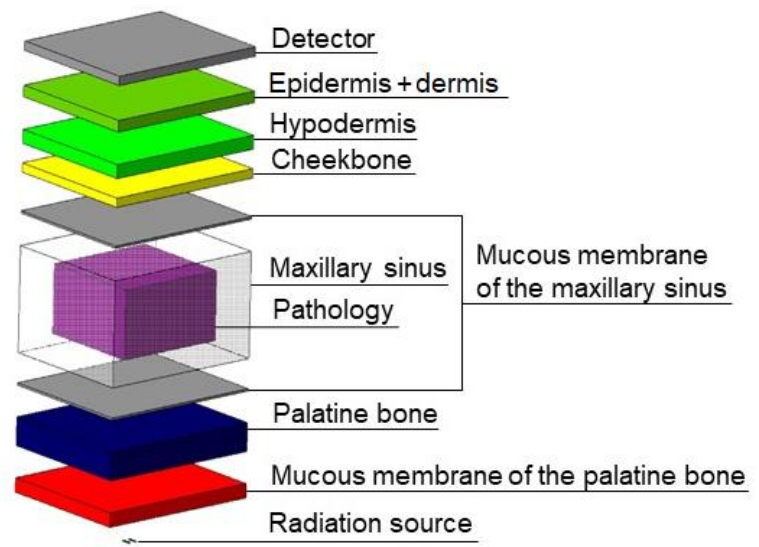

Figure 1. The scheme of the developed model.

At the stage of the model creation, the thicknesses and sizes of tissue layers for female and male, as well as the absorption and scattering coefficients of the tissues were set. Pathological changes in the form of tumor tissues and cystic fluid were considered. Simulation was carried out for radiation sources of two wavelengths equal 650 and $850 \mathrm{~nm}$. The number of simulated photons was $10^{6}$. The probe radiation power was $8 \mathrm{~mW}$. The optical properties of the epidermis, dermis, bone tissue, mucous membranes and pathologies in the form of cystic fluid and tumor are considered. The optical characteristics of the biological tissues used in the simulation are presented in Table 1.

Table 1. The optical characteristics of the biological tissues

\begin{tabular}{|c|c|c|c|}
\hline Biological tissue layer & Wavelength $\lambda, \mathrm{nm}$ & Absorption coefficient $\mu_{a}, \mathrm{~mm}^{-1}$ & Reflection coefficient $\mu_{s}, \mathrm{~mm}^{-1}$ \\
\hline \multirow{2}{*}{ 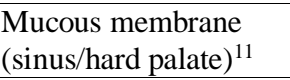 } & 650 & 0.05 & 0.8 \\
\hline & 850 & 0.075 & 1.2 \\
\hline \multirow{2}{*}{$\begin{array}{l}\text { Zygomatic/Palatine } \\
\text { bone }\end{array}$} & 650 & 0.011 & 1.873 \\
\hline & 850 & 0.007 & 2.113 \\
\hline \multirow[t]{2}{*}{ Cystic fluid $^{3,4}$} & 650 & 0.022 & 1.34 \\
\hline & 850 & 0.027 & 0.95 \\
\hline \multirow[t]{2}{*}{ Tumor $^{14}$} & 650 & 0.0391 & 2.17 \\
\hline & 850 & 0.0522 & 2.67 \\
\hline \multirow[t]{2}{*}{ Hypodermis $^{15}$} & 650 & 0.18 & 2 \\
\hline & 850 & 0.1 & 2.7 \\
\hline \multirow[t]{2}{*}{ Epidermis+dermis $^{16}$} & 650 & 0.17 & 3 \\
\hline & 850 & 0.2 & 3.7 \\
\hline
\end{tabular}

\section{EXPERIMENTAL RESULTS AND DISCUSSION}

Figures 2-4 show the simulation results of the probe radiation propagation (the photons path through the biological tissue and the irradiance map) for the maxillary sinus of female (a) and male (b) without pathology (Figure 2), with cystic fluid (Figure 3) and with tumor (Figure 4). 

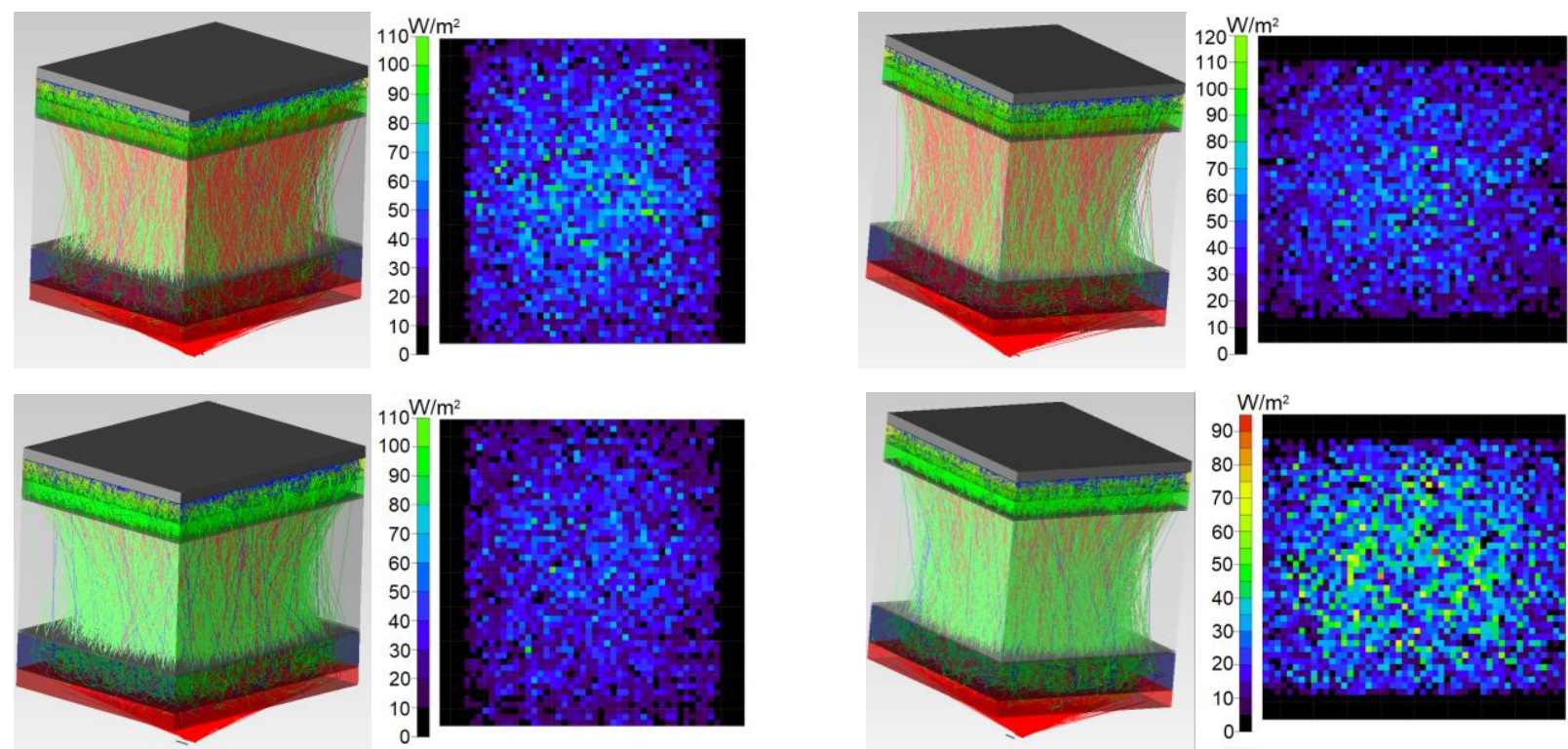

b)

Figure 2. The simulation results of the probe radiation propagation through the maxillary sinus of female (a) and male (b) without pathology at the wavelength of $650 \mathrm{~nm}$ (above) and $850 \mathrm{~nm}$ (below). The lines indicate the passage of individual photons through the tissue.
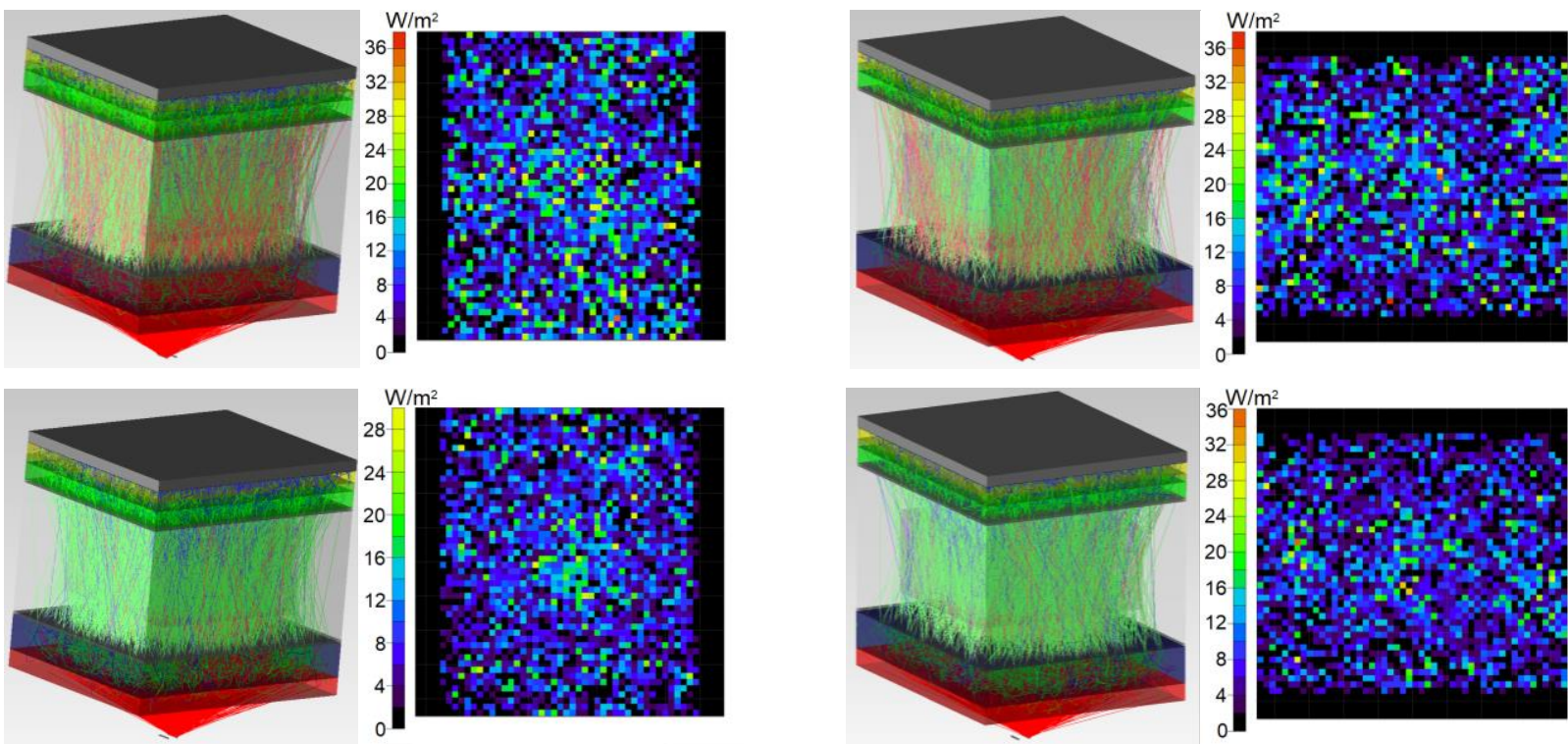

a)

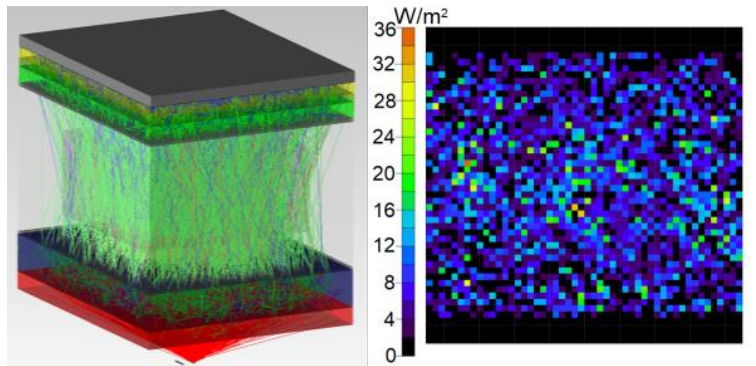

b)

Figure 3. The simulation results of the probe radiation propagation through the maxillary sinus of female (a) and male (b) with cystic fluid at the wavelength of $650 \mathrm{~nm}$ (above) and $850 \mathrm{~nm}$ (below). 


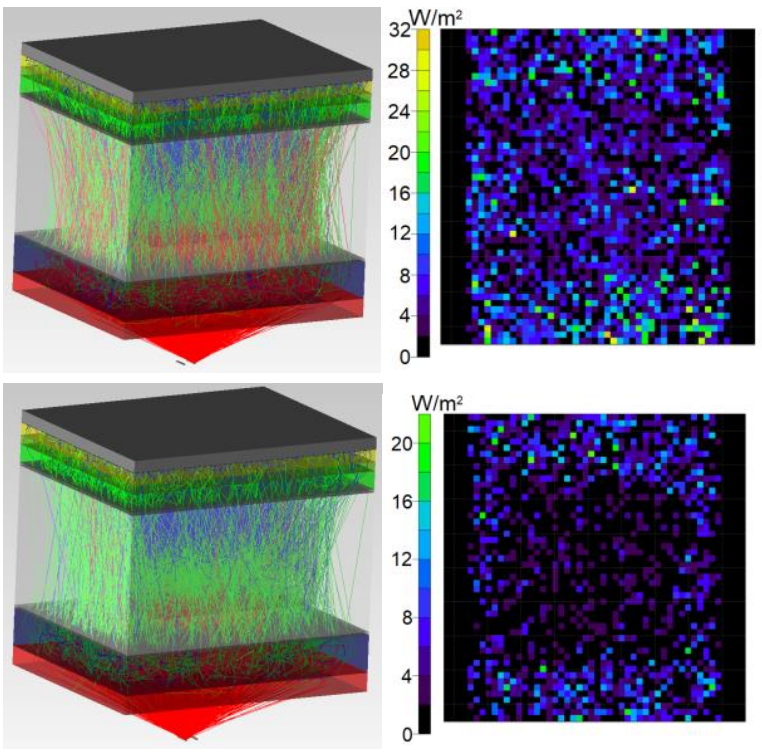

a)
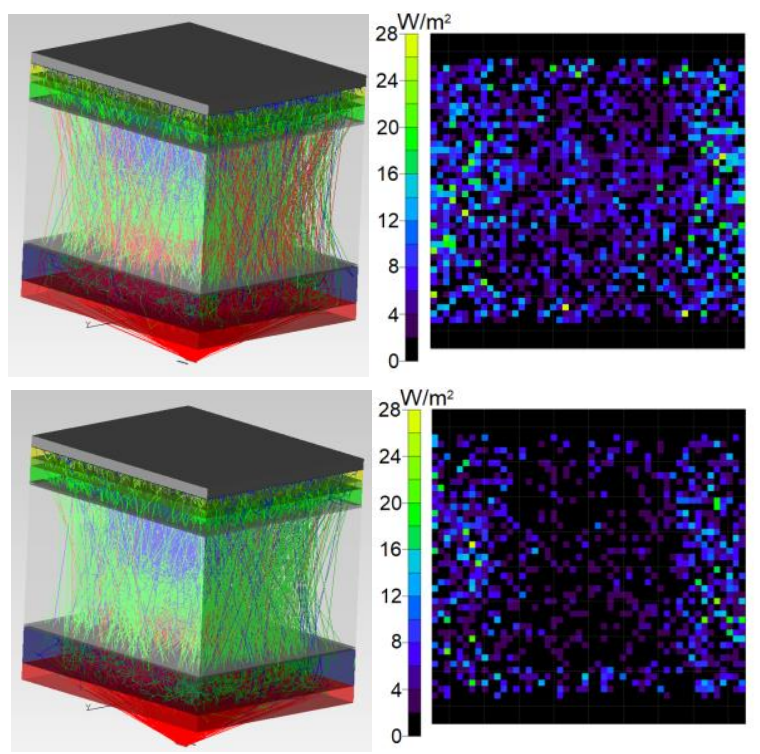

b)

Figure 4. The simulation results of the probe radiation propagation through the maxillary sinus of female (a) and male (b) with tumor at the wavelength of $650 \mathrm{~nm}$ (above) and $850 \mathrm{~nm}$ (below).

The simulation results showed a decrease in the radiant intensity at the detector (radiant power) when the radiation is passed through the biological tissues with pathology and at different values of the thickness of the bone tissue and skin, the sinuses size. Figure 5 shows the dependences of the change in the power (intensity) of radiation coming to the camera detector on the change in the hypodermis thickness and the presence of pathologies in the sinuses of female and male for wavelengths of $650 \mathrm{~nm}$ and $850 \mathrm{~nm}$.

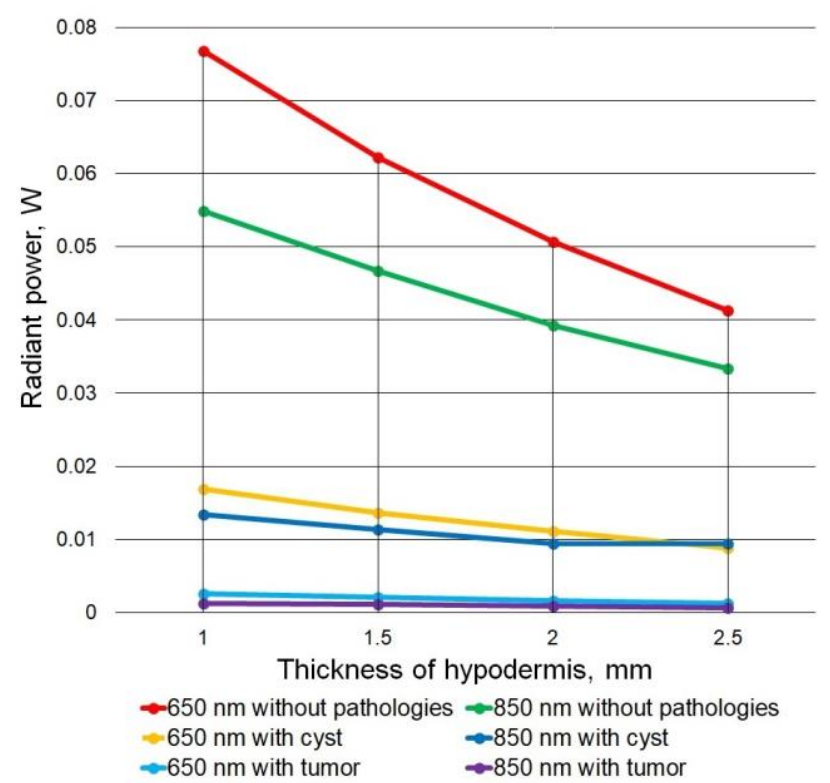

a)

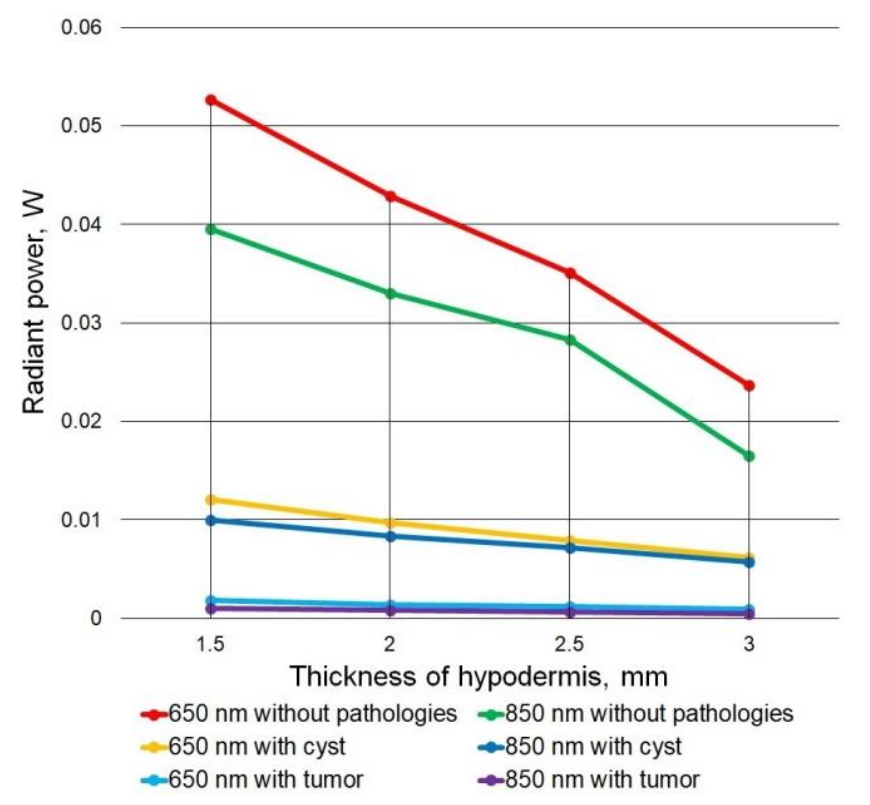

b)

Figure 5. The dependences of the change in the power (intensity) of radiation coming to the camera detector on the change in the hypodermis thickness and the presence of pathologies in the sinuses of female (a) and male (b) for wavelengths of $650 \mathrm{~nm}$ and 850 nm. 
It was found, that in the near-infrared region $(850 \mathrm{~nm})$ the decline was more pronounced and was observed in both male and female. The addition of the pathological change to the simulated object in the form of a cyst fluid or tumor produced to an even more pronounced decrease in the signal. Thus, in the near-infrared range, the signal power at the detector was lower in case of passing through the cystic formation (in female without the cyst $-0.076 \mathrm{~W}$, with a cyst fluid $-0.016 \mathrm{~W}$; in male without the cyst fluid $-0.064 \mathrm{~W}$, with a cyst $-0.010 \mathrm{~W}$ ).

The obtained results demonstrate the relationship of the recorded signals with the optical properties of the object of study, namely, with the high absorbing properties of the cystic fluid in the near-infrared range ${ }^{3,4}$, with a thickening of the sinus mucosa layer during pathology ${ }^{11}$, and with a difference in bone tissue thickness and the maxillary sinus size of female and male ${ }^{16}$. The identified factor is one of the diagnostic criteria for the separation of normal and pathological conditions of the maxillary sinus.

\section{CONCLUSION}

The obtained results help to understand the propagation of light through the complex structure and bring the essential criteria to be used to adjust the parameters of the probe and measuring parts of the device for the realization digital diaphanoscopy. Modernization of the device allows to provide equality of scattering pattern of light for different patients and the possibility of their subsequent comparison.

\section{ACKNOWLEDGMENT}

The work was supported by the grant of the President of the Russian Federation for state support of young Russian scientists № MK-2634.2019.8.

\section{REFERENCES}

[1] Remington, J. S., "Management of Community-Acquired Tract Infections," Clin. Infect. Dis. 39(3), 141 (2004).

[2] Kanwar, S. S., Mital, M., Gupta, P. K., Saran, S., Parashar, N., and Singh, A., "Evaluation of paranasal sinus diseases by computed tomography and its histopathological correlation," J Oral Maxillofac Radiol 5(2), 46-52 (2017).

[3] Jacques, S. L., "Optical properties of biological tissues: a review," Phys Med Biol 58(11), R37-R61 (2013).

[4] Peters, V. G., Wyman, D. R., Patterson, M. S., and Frank, G. L., "Optical properties of normal and diseased human breast tissues in the visible and near infrared," Phys Med Biol 35(9), 1317-1334 (1990).

[5] Gracco, A., Lombardo, L., Cozzani, M., and Siciliani, G., "Quantitative evaluation with CBCT of palatal bone thickness in growing patients," Prog Orthod 7(2), 164-174 (2006).

[6] Kang, S., Lee, S. J., Ahn, S. J., Heo, M. S. and Kim, T. W., "Bone thickness of the palate for orthodontic miniimplant anchorage in adults," Am J Orthod Dentofac Orthop 131(4), 74-81 (2007).

[7] Bryanskaya, E., Makovik, I., Bukin, A., Bibikova, O., Shuraev, B. M., Minet, O., Zabarilo, U., Dunaev, A. and Artyushenko, V., "Diagnosis of inflammatory diseases of the paranasal sinuses using digital diaphanoscopy," Proc. SPIE 11073, 110731P (2019).

[8] Dremin V. V., Dunaev A. V. "How the melanin concentration in the skin affects the fluorescence-spectroscopy signal formation," J Opt Technol 83(1), 43-48 (2016).

[9] Rafailov I. E., Dremin V. V., Litvinova K. S., Dunaev A. V., Sokolovski S. G., and Rafailov E. U., "Computational model of bladder tissue based on its measured optical properties," J Biomed Opt 21(2), 025006 (2016).

[10] Rafailov I., Palmer S., Litvinova K., Dremin V., Dunaev A., and Nabi G., "A novel excitation-emission wavelength model to facilitate the diagnosis of urinary bladder diseases," Proc. SPIE 9303, 93030W (2015).

[11] Bashkatov, A. N., Genina, E. A., Kochubey, V. I., Tuchin, V. V., Chikina, E. E., Knyazev, A. B., and Mareev, O. V., "Optical properties of mucous membrane in the spectral range 350-2000 nm," Opt Spectrosc 97(6), 978-983 (2004).

[12] Bashkatov, A. N., Genina, E. A., Kochubey, V. I., and Tuchin, V. V., "Optical properties of human cranial bone in the spectral range from 800 to $2000 \mathrm{~nm}$," Proc SPIE 6163, 616310 (2006). 
[13] Genina, E. A., Bashkatov, A. N. and Tuchin, V. V., "Optical clearing of cranial bon," Adv Opt Technol 2008, 1-8 (2008).

[14] van Veen, R, Sterenborg, H. J. C. M, Marinelli, A. W, and Menke-Pluymers, M. B. E. "Intraoperatively assessed optical properties of malignant and healthy breast tissue used to determine the optimum wavelength of contrast for optical mammography," J Biomed Opt 9(6), 1129-1136 (2004).

[15] Bashkatov, A. N., Genina, E. A. and Tuchin, V. V., "Optical properties of skin, subcutaneous, and muscle tissues: A review," J Innov Opt Health Sci 04(01), 9-38 (2011).

[16] Teke, H. Y., Duran, S., Canturk, N., and Canturk, G., "Determination of gender by measuring the size of the maxillary sinuses in computerized tomography scans," Surg Radiol Anat 29(1), 9-13 (2007). 